\title{
HABITAÇÃO EM PROJETOS DE URBANIZAÇÃO DE ASSENTAMENTOS PRECÁRIOS EM BELÉM/PA
}

\author{
Monique Bentes Machado Sardo Leão \\ Faculdade Estácio Belém, Brasil \\ Programa de pós-graduação em arquitetura e urbanismo, Universidade Federal do Pará, Brasil \\ monique.bentes@gmail.com
}

\section{Victória Regina Barros Corrêa}

Faculdade Estácio Belém, Brasil

victoria.bcorrea@gmail.com

\section{Vitória Queiroz do Nascimento}

Faculdade Estácio Belém, Brasil

vitoriaqueiroz21@hotmail.com

\section{Sâmya Raquel Oliveira}

Faculdade Estácio Belém, Brasil

samya.arquitetura@gmail.com

\begin{abstract}
RESUMO
Belém/PA, cidade amazônica, no Norte do Brasil, apresenta dados expressivos em relação a presença de assentamentos precários, historicamente, a cidade teve uma formação urbana marcada pela desigualdade socioespacial, em ocupações informais em áreas de várzeas. As baixadas, como são conhecidas, representam áreas de moradia da população pobre que habitam palafitas precárias e com deficiência de infraestrutura e serviços urbanos. Desta forma, projetos que visam a urbanização e macrodrenagem implicam um número alto de remoções, demandando soluções para o reassentamento. $O$ objetivo do trabalho é analisar as urbanizaçõesde assentamentos precários em Belém/PA, executadas recentemente, ediscute-se as principais problemáticas referente ao reassentamento das famílias atingidas pelas obras.
\end{abstract}

Palavras-chave:Reassentamento, urbanização de assentamentos precários, Belém/PA Linha de Investigação: 3. Dinâmicas urbanas Tópico: Assentamentos precários

\section{ABSTRACT}




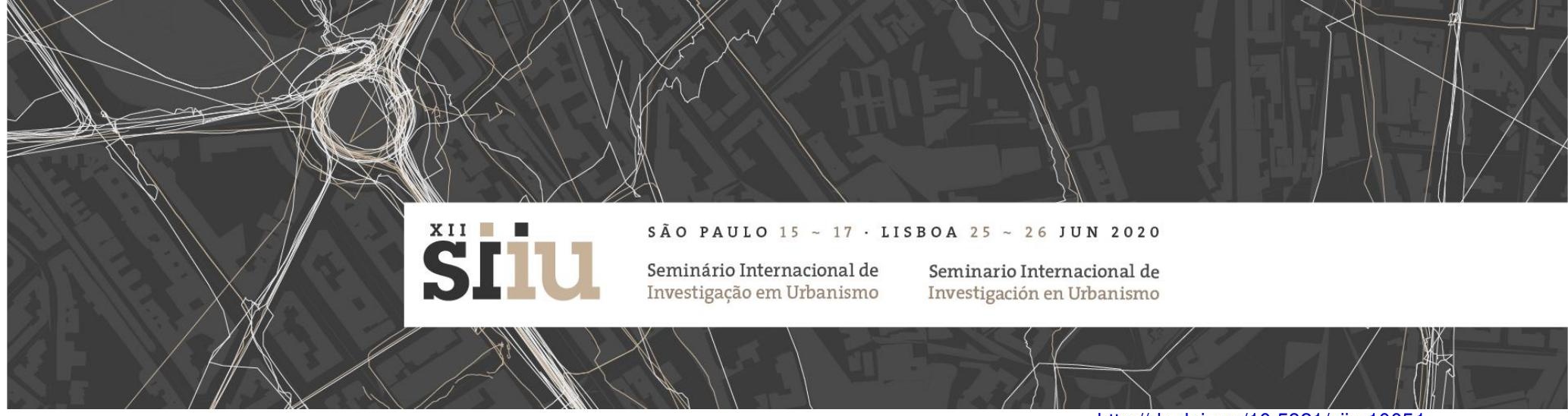

http://dx.doi.org/10.5821/siiu.10051

Belém/PA, an Amazonian city, in the North of Brazil, presents expressive data regarding the presence of precarious settlements, historically, a city that had an urban formation marked by socio-spatial inequality, in informal occupations in areas of several cities. As waterlogged, as they are identified, they represent housing areas for the poor population that live in precarious stilts and with difficulty in infrastructure and urban services. In this way, projects aimed at urbanization and macrodrainage involve a high number of emotions, demanding solutions for resettlement. The purpose of the paper is to analyze the urbanization of precarious settlements in Belém/PA, recently carried out, and discusses the main issues related to the resettlement of families affected.

Keywords: Resettlement, urbanization of precarious settlements, Belém/PA Thematic clusters: 3 . Urban dynamics Topic: Precarious settlements 



\section{SÃO PAULO 15 17 LISBOA $25 \sim 26$ JUN 2020

Pinheiro (et. al, 2007) cita que a economia baseada em extrações de drogas do sertão, se manteve nos séculos XVII e XVIII, e teve sua queda na metade do século XIX, período,onde a extração de látex tornou-se a principal economia da região, e fomentou transformações territoriais nas cidades amazônicas. Neste período, Belém recebeu investimentos em infraestrutura urbana e embelezamento paisagístico, destacandose o plano de expansão para a malha urbana, que previa o arrumamento por meio de um desenho ortogonal para a área da primeira légua patrimonial da cidade, com abertura de vias e também da estrada de ferro Belém-Bragança, o que fez com que pequenos núcleos agrícolas se formassem além da área de expansão, em áreas que hoje são os municípios de Ananindeua e Benevides, integrantes da atual região metropolitana de Belém (Pinheiro, et. al, 2007).

Com o plano de expansão e a economia crescente, a população de alta renda se alojou com seus palacetes e casarões nos bairros urbanizados, situados em terrenos altos e distantes dos pântanos e alagadiços, que representavam uma barreira natural para a expansão urbana planejada, desta forma o traçado retilíneo avançava até encontrar as áreas alagadiças. Após a década de 1950, observa-se o crescimento populacional de Belém, e as áreas mais altas e urbanizadas da cidade acabam tornando-se cada vez mais caras, o que colaborou para o avanço da ocupação das várzeas, que mesmo apresentando dificuldades ambientais, tornaram-se alternativas para a moradia da população pobre.

Segundo o Censo de 2010 (Instituto Brasileiro de Geografia e Estatística - IBGE), as baixadas belenenses são identificadas como aglomerados subnormais (ver figura 4), e correspondem as áreas com as densidades mais altas da cidade (em tornode 300-500 hab./ha), e de presença de população com renda mais baixa (com predomínio de até 2 salários mínimos). Segundo a pesquisa realizada por PINHEIRO (et. al, 2016),"baixadas"é a tipologia de assentamento precário mais antiga de periferia urbana moderna da região metropolitana de Belém, sendo caracterizada por apresentar elementos já clássicos da definição teórica de áreas periféricas, como:"populaçãomigrante, pobre e de baixa escolaridade; sítio físico com fragilidade ambientale/ou titularidade pública da terra; localização relativamente próxima àscentralidades econômicas das cidades"(Pinheiro, et al, 2016, p.199).Conforme a mesma pesquisa, haveriam mais duas tipologias que caracterizam os assentamentos precários em Belém: as invasões e os assentamentos ribeirinhos. As invasões são assentamentos oriundos de ocupação irregular na área de expansao urbana, sobretudo entre meados da década de 1980 e a primeira metade dosanos 1990, e estariam relacionadas a eixos viários de rodovias, enquanto assentamentos ribeirinhos são referentes a comunidades tradicionais que ocupam zonas rurais-ribeirinhas, em geral na região das ilhas de Belém.

\section{Os rios e as cidades paraenses}

Sendo uma cidade às margens da Baía do Guajará e de muitos rios e igarapés cortando seu relevo, Belém, sempre teve em sua história uma relação direta com seus rios. Segundo Ponte (2015), é notável a influência dos cursos d'água na paisagem natural e contexto urbano da cidade. Esses mesmos rios já foram o principal canal de transporte para negociações e trânsito de pessoas, e ainda hoje exercem esse papel em muitas comunidades interioranas, situadas as margens de rios e igarapés. A cultura ribeirinha e de palafitas ainda é forte e presente na região amazônica, com uma conexão direta com a água, essas comunidades têm relação de dependência direta com seus rios, muitas vezes como único meio de interação com a capital ou cidades 


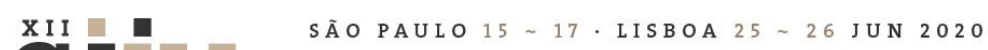

Seminário Internacional de Investigação em Urbanismo

Seminario Internacional de Investigación en Urbanismo

vizinhas. Essa relação com a água está hoje presente na capital paraense, e é expressa pelas atividades portuárias, feiras e mercados populares ao longo de sua orla fluvial, além das comunidades em palafitas, formadas por uma população pobre que migram em busca de mudança de vida e ascendência social.

Em geral, os moradores das baixadas são migrantes das regiões das ilhaspróximas à cidade e de municípios do interior do estado (Abelém,1988). No ambiente urbano, essa população reproduziu um padrão ribeirinho na forma urbana e arquitetônica das baixadas, por meio de edificações palafíticas e pontes, chamadas de estivas. Em um contexto rural, os ribeirinhos praticam, nas margens dos rios amazônicos, um modo de vida baseado em sistemas derotatividade da cultura agrícola, extrativismo, caça e pesca, suas habitações são espaçadas e as comunidades de baixa densidade, representando baixo impacto ambiental e interessante solução que se integra ao contexto natural das várzeas. Porém, em situação de alta densidade, pobreza e deficiência de infraestrutura, o ribeirinho urbano é estigmatizado, e sua arquitetura condenada (Leão, 2013).

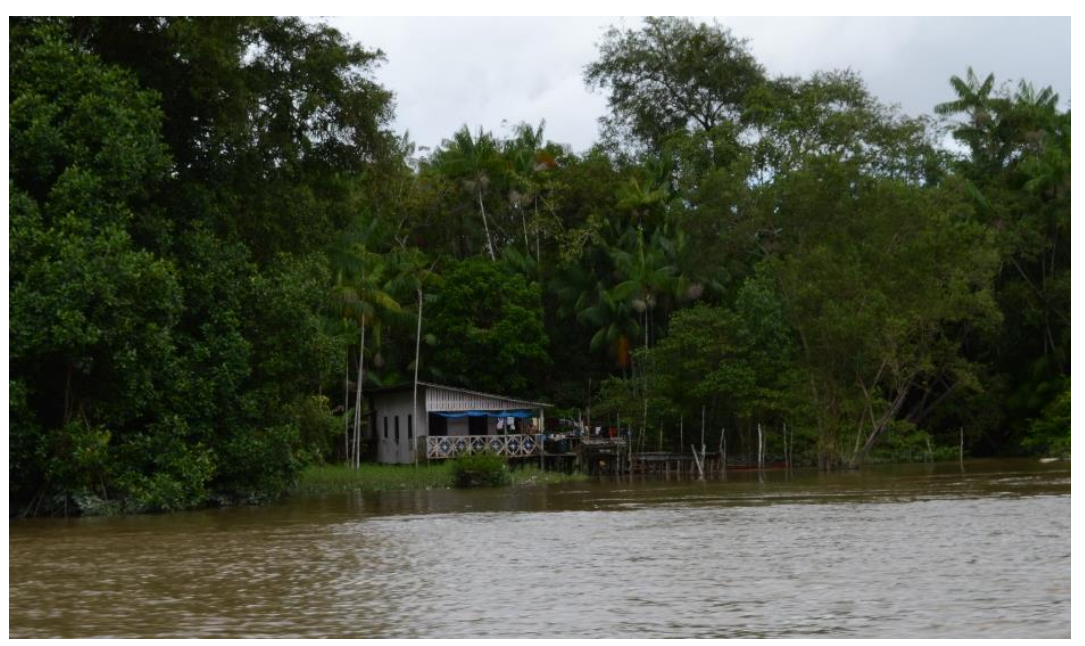

Fig 1- Habitação em palafita no contexto rural localizada na região das ilhas em Belém/PA. Foto: Monique Leão, 2015. 


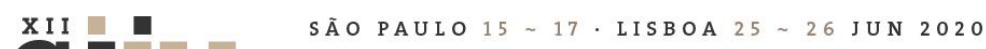

\section{Seminário Internacional de Investigação em Urbanismo \\ SIIUL \\ (1)}

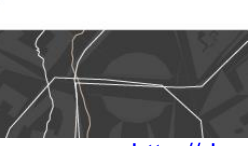

http://dx.doi.org/10.5821/siiu.10051

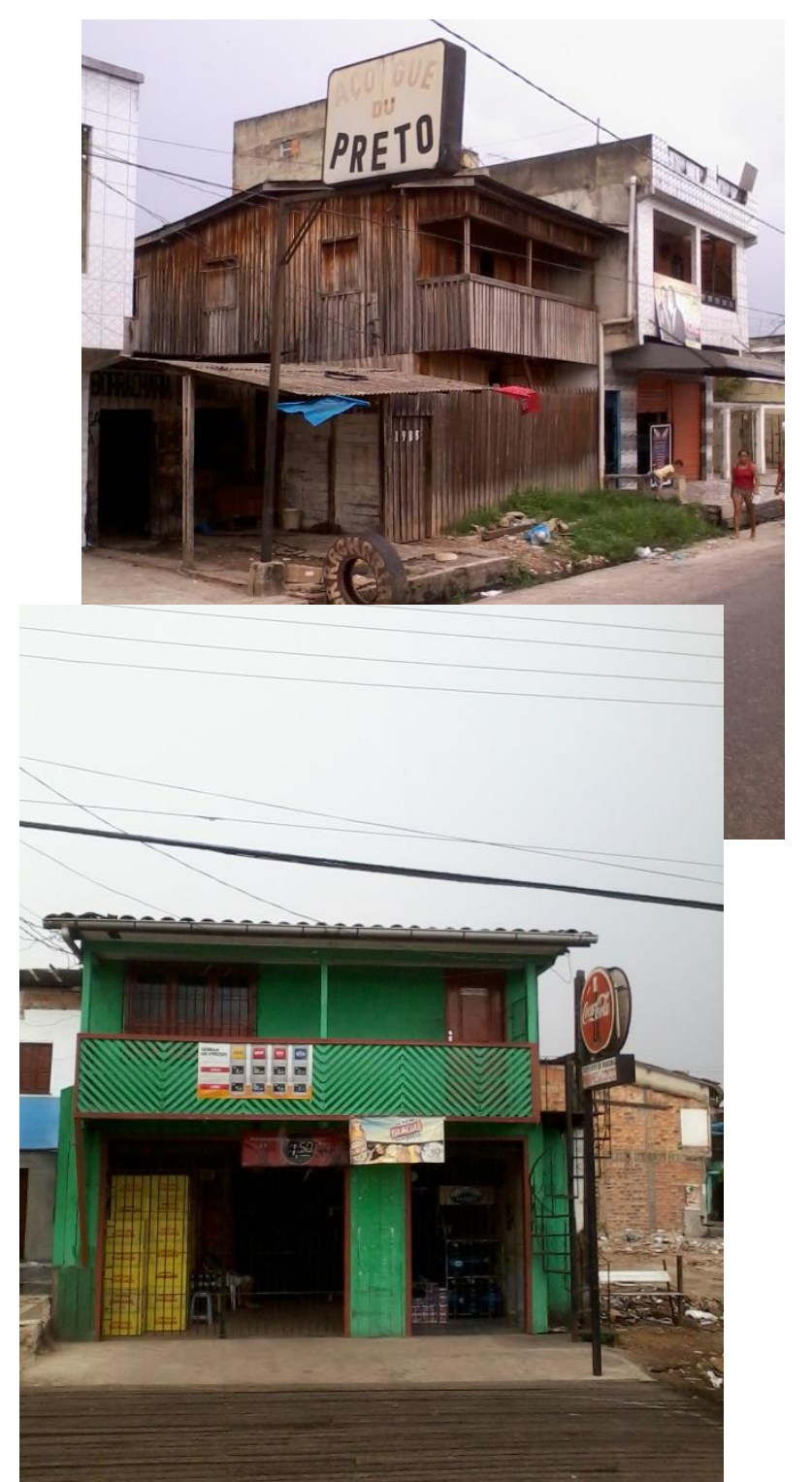

Fig 2 e 3 - Habitações com características ribeirinhas nas baixadas de Belém. Foto: Monique Leão, 2012.

A relação com o rio vem mudando drasticamente conforme a visão que se tem de urbanização e expansão da cidade. Com a ideia de crescimento da malha urbana de forma mais retilínea possível, a forma natural dos rios e várzeas foram ignorados, sendo retificados, canalizados e alguns casos aterrados. Soluções que podem ser questionadas pelas problemáticas ambientais que já estão afetando a infraestrutura e a funcionalidade da cidade, pois é cada vez mais frequente alagamentos, sobretudo nos bairros localizados nas áreas mais baixas.

Atualmente, segundo o Código Florestal brasileiro (Lei oㅜ 12.651/2012), a vegetação nativa das margens dos cursos d'águas são consideradas APP's (Área de Proteção Permanente), sendo recomendada sua 


\section{SÃO PAULO15 17 LISBOA $25 \sim 26$ JUN 2020}

manutenção ou recuperação em situação de degradação. Desta forma, observa-se em Belém, um conflito entre o avanço da expansão urbana (em geral de maneira irregular) e as áreas de proteção ambiental. Neste sentido, torna-se uma das características dos assentamentos precários em Belém,e problemática entre ocupação irregular e a presença deAPP's, gerando a necessidade de planos urbanísticos abrangentes no sentido de urbanizar, recuperar áreas ambientais e reassentar comunidades. O que se torna um desafio para a gestão urbana da cidade, pois, historicamente adotava-se um modelo de urbanização que transformou cursos d'água em elementos da drenagem urbana, que sem um sistema de tratamento de esgoto funcionando perfeitamente, gerou degradação e poluição ambiental:

"Com uma porcentagem tão significativa de aglomerados subnormais e com as características de assentamentos em áreas ambientalmente sensíveis na cidade, os projetos de urbanização e saneamento realizados em assentamentos precários em Belém têm sido intervenções de melhoria urbanística parcial, priorizando-se o aspecto da drenagem. O acompanhamento dos projetos indica problemas de diferentes ordens para a superação dessa limitação na capacidade de promover a urbanização integrada e avançar no sentido de incorporação de soluções projetuais e técnicas de drenagem que possam aliar a melhoria das condições de urbanização e de recuperação ambiental, em especial nas APP's." (Rodrigues, Tavares, Miranda, 2016, p.22)

\section{A ação do estado nos assentamentos precários em Belém/PA.}

A intervenção do Estado nas baixadas é justificada pelas problemáticas de saneamento, visando a introdução de infraestrutura e urbanização, o que ocorre desde meados da década de 1960. A principal estratégia deintervenção sobre essas áreas tem sido baseada em projetos de macrodrenagem que também favorecema integração viária dacidade. Importante citar que dentre os objetivos dos primeiros projetos de recuperação de baixadas estão também à ampliaçãodo estoque de terras infraestruturadas para a expansão imobiliária e investimentos quepossibilitassem melhoria de qualidade de moradia em áreas alagadas (PINHEIRO et al,2007).Muitas intervenções não foram pensadas para os moradores das áreas, e sim para favorecer o mercado imobiliário, promovendo remoções e gentrificações de áreas mais próximas ao centro.

As remoçõesgeram conflitos, resistências e indignação pelos atingidos. Grandes projetos de macrodrenagem propuseram reassentamentos, muitas vezes para conjuntos periféricos, trazendo problemáticas para as famílias se adaptarem, principalmente pela distância da casa-trabalho. Desde o final da década de 1980 são elaborados planos que tentam viabilizar reassentamentos mais próximos ou na área atingida (Leão, 2013).O que nem sempre é executado de fato, gerando descontentamento da população atingida.

Atualmente, Belém possui um número considerável de projetos de urbanização de assentamentos precários, que se destacam pela inserção de infraestrutura, urbanização e moradia digna para essa parcela da população. Em geral, são projetos que foram viabilizados pelo PAC (Programa de Aceleração do Crescimento), programa criado pelo Governo Federal em 2007 com o intuito de financiar grandes obras de 


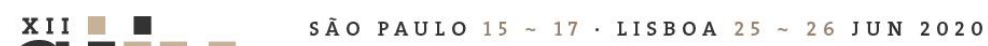

infraestrutura, incluindo urbanização de favelas (Rodrigues, Araújo, Castro, 2016). Desta forma, Belém recebeu recursos do PAC, para a execução de obras de urbanização de assentamentos precários, saneamento ambiental e macrodrenagem. Os recursos viabilizaram execução de ações integradas (implantação de infraestrutura urbana, produção habitacional e de equipamentos urbanos, regularização fundiária), o que na perspectiva de intervenção em assentamentos, que apresentam diversas necessidades, era considerado um avanço (Rodrigues, Araújo, Castro, 2016).

Em Belém, a responsabilidade pelos projetos PAC Urbanização de Assentamentos Precários (PAC-UAP)foi dividida entre o governo Estadual e Municipal, na esfera estadual, destacou-se a atuação por meio da Companhia de Habitação do Estado do Pará (COHAB/PA) que ficou responsável por alguns dos projetos a serem feitos na Região, contudo a COHAB/PA demonstrou falta de experiência para a gestão de grandes

urbanizações em áreas precárias, que exigiam um nível de complexidade maior do que a atuação de produção de conjuntos habitacionais na qual o órgão estava habituado. Na esfera municipal, observou-se a atuação de várias secretariais municipais, como a secretaria municipal de habitação (SEHAB), secretaria municipal de urbanismo (SEURB) e secretaria municipal de saneamento (SESAN), no entanto, sendo notada uma falta de integração entre os órgãos para questões dos projetos PAC-UAS (Leão, 2018).

Entre os anos de 2007 e 2011 foram realizados 283 contratos pelo PAC para a RMB, dentre esses 24 são voltados para a urbanização de assentamentos precários, sendo que a cidade de Belém recebeu 15 desses contratos (Rodrigues, Araújo, Castro, 2016). A localização dos projetos PAC-UAP em Belém pode ser observada na figura a seguir: 


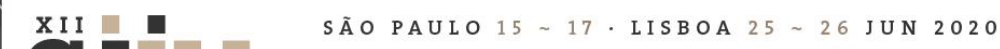

Seminário Internacional de

Seminario Internacional de Investigação em Urbanismo

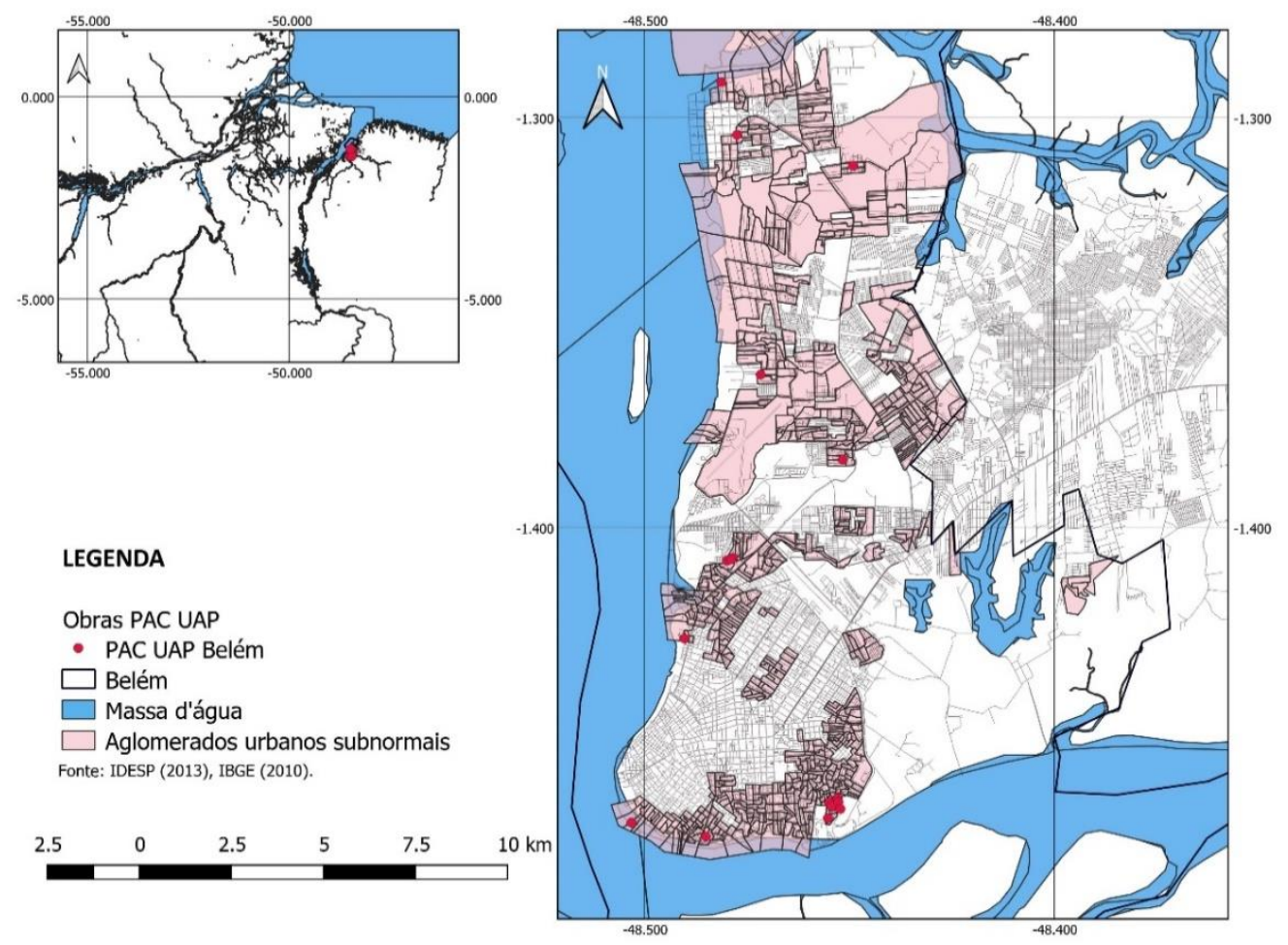

Fig4 - Localização de projetos PAC-UAP em Belém/PA. Fonte: IDESP-PA (2013), IBGE (2010), adaptado por autores.

Como o mapa demonstra, os projetos PAC-UAP, localizam-se em áreas consideradas aglomerados subnormais pelo IBGE, ou seja, áreas que são identificadas com precariedades infraestruturais, pobreza e irregularidade da posse. O mapa também explicita 0 alto percentual de territórios considerados nesta situação, demonstrando os desafios para o enfrentamento das desigualdades socioespaciais na cidade.

\subsection{Estudos de caso: reassentamentos em urbanizações de baixadas em Belém/PA}

Nesta sessão do trabalho aborda-se sobre projetos de urbanização que estão sendo executados atualmenteem Belém, destacando-se o reassentamento de famílias. Serão apresentados, os seguintes estudos de casos:

\subsubsection{Vila da Barca}

O projeto da Vila da Barca foi uma iniciativa de 2002, quando o atual prefeito de Belém (Edmilson Rodrigues) fez o convite ao arquiteto Luiz Fernando Almeida Freitas, arquiteto chefe da CoOperaAtiva, para concepção do projeto de intervenção da Vila da Barca, uma comunidade palafítica localizada na área central de Belém. Em 2003, após confirmação e autorização dos órgãos responsáveis, o escritório firmou parceria com o escritório paraense Meia Dois Nove eseguiu aperfeiçoando os estudos preliminares e fazendo aprimeira entrega de projeto a SEHAB/Belém (Afalo,2016). As primeiras unidades foram entregues em 2008, porém 


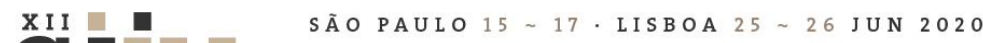

Seminário Internacional de Investigação em Urbanismo

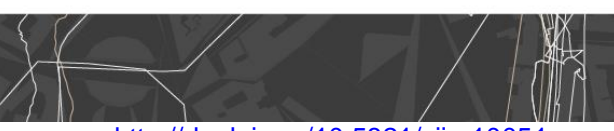

houve necessidade na época de revisão de projeto e com isso, adiando a execução das outras fases do projeto. O residencial Vila da Barca foi revisado em 2011, já com recursos do PAC, quando ocorreram mais entregas de unidades habitacionais em 2016 (Afalo,2016).

Segundo Souza e Santana (2013) o projeto tinha por objetivo realizar intervenção urbana e infraestrutura de habitação de abrangência de $73.110 .097 \mathrm{~m}^{2}$, prevendo a construção de 624 unidades habitacionais para os remanejados, além de unidades comerciais e serviços. Segundo Freitas (2014) a área destinada à construção das habitações foi equivalente a $81.380 \mathrm{~m}^{2}$ servindo a mesma quantidade de habitantes, sendo necessária a aquisição de um terreno em solo firme que fazia fronteira com a comunidade para que se tivesse uma resolução rápida para o problema de insalubridade daquele local.

Segundo o jornal Folha de São Paulo (2019), pouco mais de 150 unidades foram entregues desde o primeiro prazo, que era o ano de 2007, e nos últimos oito anos somente 12 unidades foram entregues, por consequência o local acabou reconhecido pelos entulhos e ponto de venda de drogas, o que agrava a situação dos moradores remanejados. Boa parte da comunidade ainda é em vilas palafíticas.

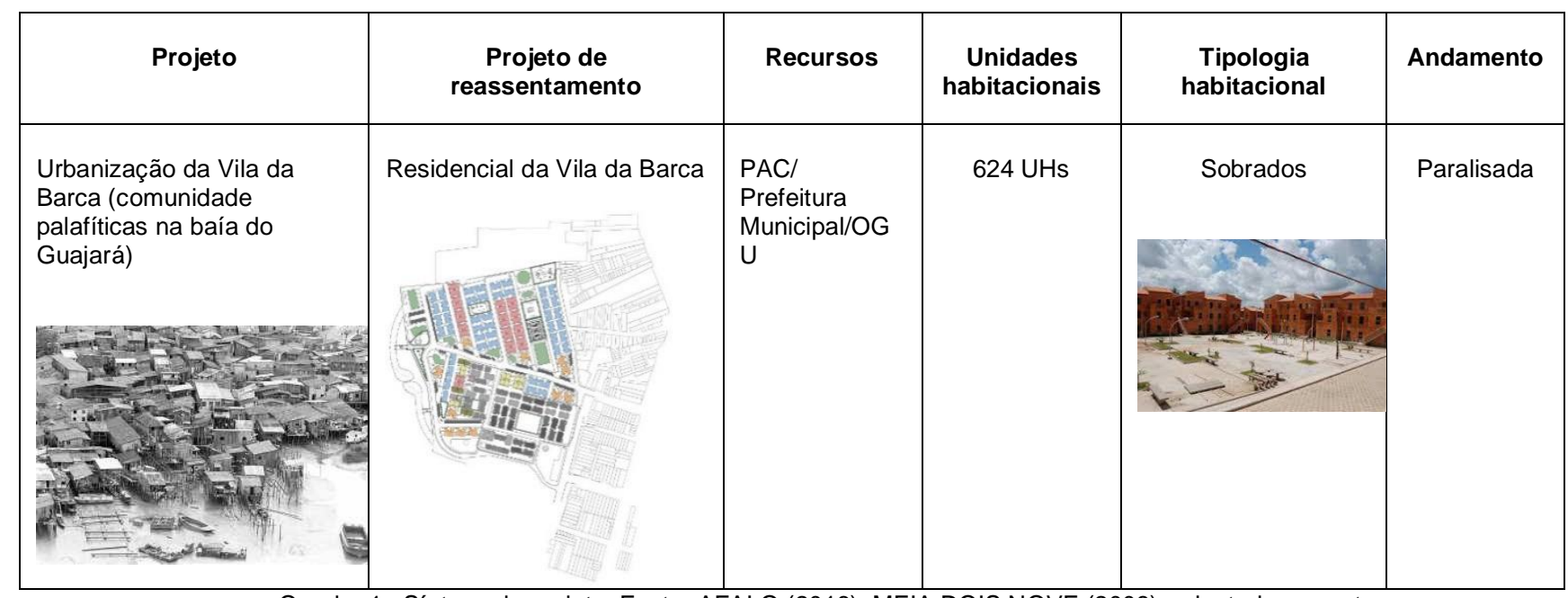

Quadro 1- Síntese do projeto. Fonte: AFALO (2016); MEIA DOIS NOVE (2008), adaptado por autores.

\subsubsection{Residencial Liberdade 1 e 2}

O Residencial Liberdade foi um projeto de reassentamento desenvolvido em 2008 pela COHAB/PA, novamente com a parceria do escritório paraense Meia Dois Nove e o escritório carioca Cooperativa. $O$ projeto inspirado no residencial Vila da Barca, foi criado para abrigar moradores atingidospelas obras de 


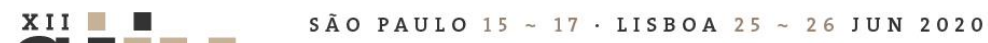 \\ Seminário Internacional de \\ Seminario Internacional de Investigação em Urbanismo

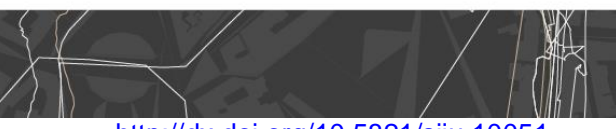

http://dx.doi.org/10.5821/siiu.10051

macrodrenagem da bacia do Tucunduba e da duplicação da Avenida Perimetral, área com alta densidade de moradias precárias, localizada próxima ao centro de Belém. O projeto habitacional foi dividido em: Residencial Liberdade 1 e 2,segundo o memorial do projeto (Meia Dois Nove, 2008), muitos dos critérios usados para a concepção de reurbanização foram pensados de maneira que houvesse integração dos habitantes, tais como uso de instalações de áreas de convívio e ambientes comuns e com equipamentos urbanos que incentivassem os moradores a usufruir dos espaços (mercado, cras, etc.).São previstos para o Residencial Liberdade 1 a produção de 276 blocos habitacionais para atender 1360 habitantes, e o Residencial Liberdade 2 seria composto por 2.028 blocos para atender 10.140 habitantes. Ainda existe previsão para que se tenha um Residencial Liberdade 3.

As obras sofreram várias paralisações, sendo que com a retomada do projeto da macrodrenagem em $2015 / 2016$, o projeto habitacional avançou até aproximadamente $60 \%$ das obras (COHAB, 2017). No entanto, ainda se encontra inconcluso até hoje, por série de problemáticas que levam a paralisações, que por sua vez levam a ocupações irregulares das unidades em construção que demandam remoções para novas retomadas das obras.

\begin{tabular}{|c|c|c|c|c|c|}
\hline Projeto urbano & Projeto de reassentamento & Recursos & $\begin{array}{c}\text { Unidades } \\
\text { habitacionais }\end{array}$ & $\begin{array}{c}\text { Tipologia } \\
\text { habitacional }\end{array}$ & Andamento \\
\hline $\begin{array}{l}\text { Projeto de macrodrenagem } \\
\text { da bacia do Tucunduba. }\end{array}$ & $\begin{array}{l}\text { Reassentamento Residencial } \\
\text { Liberdade I e II }\end{array}$ & $\begin{array}{l}\text { PAC/ Governo do } \\
\text { Estado, } \\
\text { FNHIS/OGU E } \\
\text { FGTS }\end{array}$ & $564 \mathrm{UHs}$ & Sobrados & $\begin{array}{l}\text { Em obras/ } \\
\text { Atrasado }\end{array}$ \\
\hline
\end{tabular}

Quadro 2 - Síntese do projeto. Fonte: MEIA DOIS NOVE (2008); COHAB/PA (2017), adaptado por autores.

\subsubsection{PAC - Paracuri}

O projeto PACParacuri é de 2007 efoi uma iniciativa da prefeitura municipal de Belém, localiza-se na bacia do Paracuri, na zona norte da cidade, considerada uma área de expansão urbana de Belém, destacando-se ainda pela baixa densidade e grande presença de área verde no entorno do rio Paracuri. O projeto previaa macrodrenagem,blocos habitacionais, urbanização de vias, estação de tratamento de esgoto (ETE) e áreas de lazer. Esse projeto apresenta vantagens se comparado a outros propostos para a área central de Belém, como a possibilidade de integração e articulação da urbanização, implementação de infraestrutura básica, 


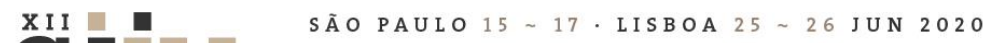

Seminário Internacional de

Seminario Internacional de

Investigação em Urbanismo

oferta de áreas de lazer distribuídas pontualmente na área e principalmente, a vantagem de manter os moradores na mesma área de origem.

Em sua totalidade o PAC-Paracurí deveria entregar 376 unidades habitacionais, em 47 blocos que contam com moradias de $38,66 \mathrm{~m}^{2}$. No entanto, o projeto até esta data, foi somente parcialmente entregue, alguns blocos já estão sendo habitados, enquanto a maioria ainda continua em fase de construção, observa-se também várias paralisações das obras, que levam a conflitos com moradores que ocupam as unidades em construção em forma de protesto, necessitando processos de remoção para continuação das obras. Considera-se que as soluções habitacionais podem ser criticadas pela moradia pequena, que não atende as necessidades das famílias, e deficiência de soluções bioclimáticas.

\begin{tabular}{|c|c|c|c|c|c|}
\hline Projeto & Projeto de reassentamento & $\begin{array}{c}\text { Recursos/ } \\
\text { financiamento }\end{array}$ & $\begin{array}{c}\text { Unidades } \\
\text { habitacionais }\end{array}$ & $\begin{array}{c}\text { Tipologia } \\
\text { habitacional }\end{array}$ & Andamento \\
\hline $\begin{array}{l}\text { PAC Paracuri - } \\
\text { Urbanização Integral da } \\
\text { Comunidade do rio } \\
\text { Paracuri } \\
\end{array}$ & $\begin{array}{l}\text { Reassentamento no bairro } \\
\text { Ponta Grossa } \\
\text { Reassentamento nos limites do } \\
\text { Parque Guajará }\end{array}$ & $\begin{array}{l}\text { PAC/ Prefeitura } \\
\text { de Belém e } \\
\text { FGTS }\end{array}$ & $\begin{array}{c}376 \text { UHs } \\
\text { UH: } 37,67 \mathrm{~m}^{2}\end{array}$ & Sobrados & Paralisado \\
\hline
\end{tabular}

Quadro 3 - Síntese do projeto. Fonte: Prefeitura de Belém, adaptado por autores.

\subsubsection{PAC - Taboquinha}

Localizado também na zona norte de Belém, o projeto da comunidade Taboquinha ficou sob responsabilidade da $\mathrm{COHAB/PA}$ e tinha como objetivo principal a remoção de famílias residentes em moradias precárias na APP, a desobstrução do igarapé Tabocal, formando três lagos com possibilidade de acesso de pequenas embarcações em função da preservação do leito natural e de alagamento do igarapé, sendo que apenas um pequeno trecho foi retificado. Foi proposta a produção de 978 Unidades Habitacionais (UH) para remanejamento das famílias deslocadas em apartamentos sobrepostos com quintal e unidades térreas. A implantação de infraestrutura urbana, incluindo redes de esgoto sanitário, abastecimento de água, energia elétrica, sistema viário, drenagem pluvial e uma Estação de Tratamento de Esgoto (ETE). E por fim, a realização de regularização fundiária (Rodrigues, Araújo, Castro, 2016). 


\section{SÃOPAULO15 17 LISBOA $25 \sim 26$ JUN 2020 \\ Seminário Internacional de Investigação em Urbanismo

\section{3}

O PAC Taboquinha é visto pelos técnicos da Caixa Econômica Federal (CEF) como um "projeto piloto" para áreas de várzea ou APP. Isso se dá devido ao tratamento do Igarapé Tabocal, com poucas retificações e a preservação da permeabilidade do igarapé, mostrando que o programa de necessidades do projeto busca recriar a relação do morador com o rio, pois faz parte da identidade ribeirinha (Rodrigues, Araújo, Castro, 2016).O projeto Taboquinha atingiu aproximadamente $80 \%$ de obras concluídas, no entanto, também apresentou conflitos com remoções, e encontra-se ainda inconcluso. A demora para o processo de construção de novas moradias e remoções é lento, ocorrendo conflitos com novos moradores que ocupam novamente trechos que já haviam sido liberados.

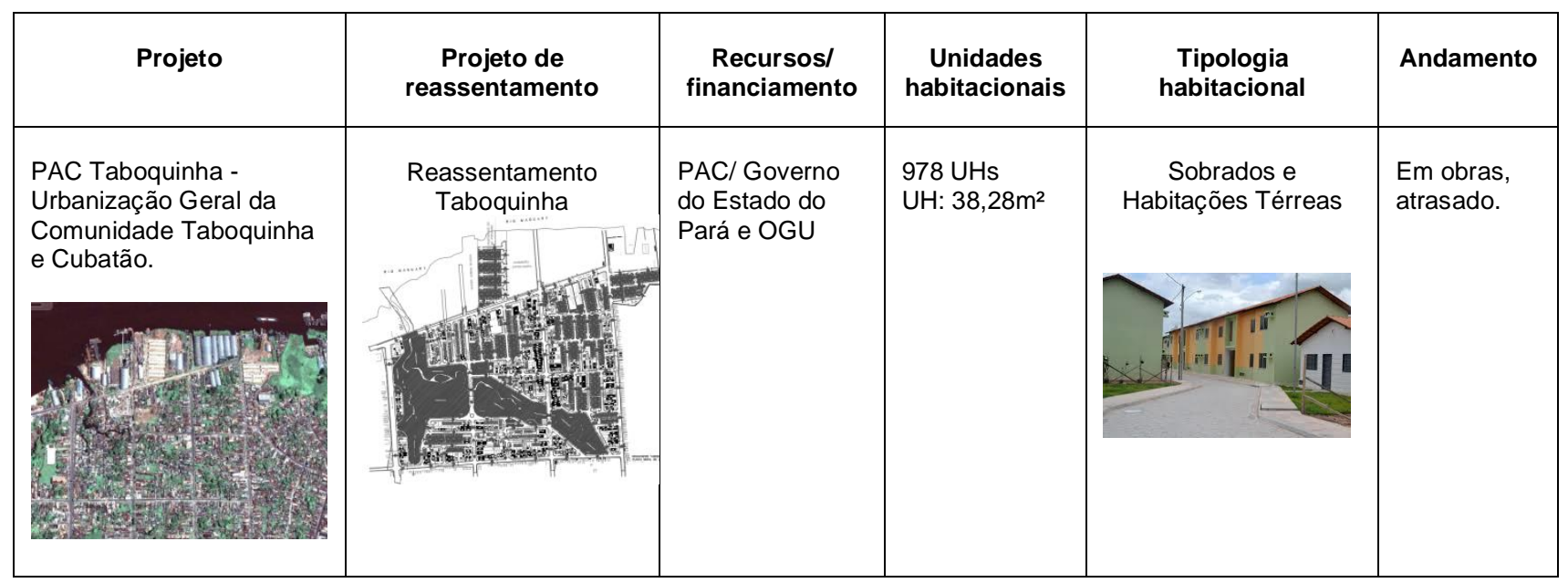

Quadro 4 - Síntese do projeto. Fonte: Rodrigues, Araújo, Castro (2016), COHAB/PA (2017), adaptado por autores.

\subsubsection{PROMABEN e Portal da Amazônia}

O Programa de Saneamento da Bacia da Estrada Nova (PROMABEN) é uma proposta da Prefeitura Municipal de Belém, através de financiamento do BID, para macrodrenagem e urbanização da bacia da Estrada Nova. Segundo o planejamento do reassentamento, seriamconstruídos dois conjuntos habitacionais na área. Devido a problemas de licitação com a construtora, as obras do conjunto foram paralisadas, evisando cumprir o prazo máximo que o BID estabelecia para que os moradores recebessem auxílio-moradia (dois anos), as famílias foram reassentadas no Residencial Comandante Cabano AntônioVinagre, bloco habitacional que seria utilizado para o reassentamento de famílias deslocadas pelasobras de duplicação da Av. João Paulo II, localizado a aproximadamente $6,5 \mathrm{~km}$ de distância da área.A proposta a princípio não foi bem aceita pela maior parte das famílias. O conjunto recebeu 115 famílias.

Complementar ao PROMABEN, o Portal da Amazônia é uma proposta de requalificação dasmargens do Rio Guamá, através de aterro de terrenos do leito do rio para a consecução de obrasviárias e parque linear, financiado com recursos federais (Ministério do Turismo e PAC), incluindoa construção de habitações em área antes ocupada na maior parte por vilas de palafitas. Foramempregadas duas formas de atendimento 


\section{SÃOPAULO15 17 LISBOA $25 \sim 26$ JUN 2020 \\ Seminário Internacional de \\ Seminario Internacional de Investigação em Urbanismo

aos deslocados: a indenização em dinheiro e o reassentamento de famílias em situação de risco, selecionadas conforme avaliação de técnicos da PMB para oResidencial Portal da Amazônia (Figura 4), localizado próximo à orla, com 221 unidades. Financiadoatravés de recursos do PAC habitação, as obras encontram-se paralisadas desde 2012. Deste, apenas um bloco foi entregue, enquanto as outras famílias, aindanão transferidas, estariam recebendo auxilio aluguel. Durante o processo, houve relatos de: falta de comunicação da Prefeitura com a população atingida;atrasos na entrega da habitação e do auxílio-moradia; indenizações baixas e negociações arbitrárias.

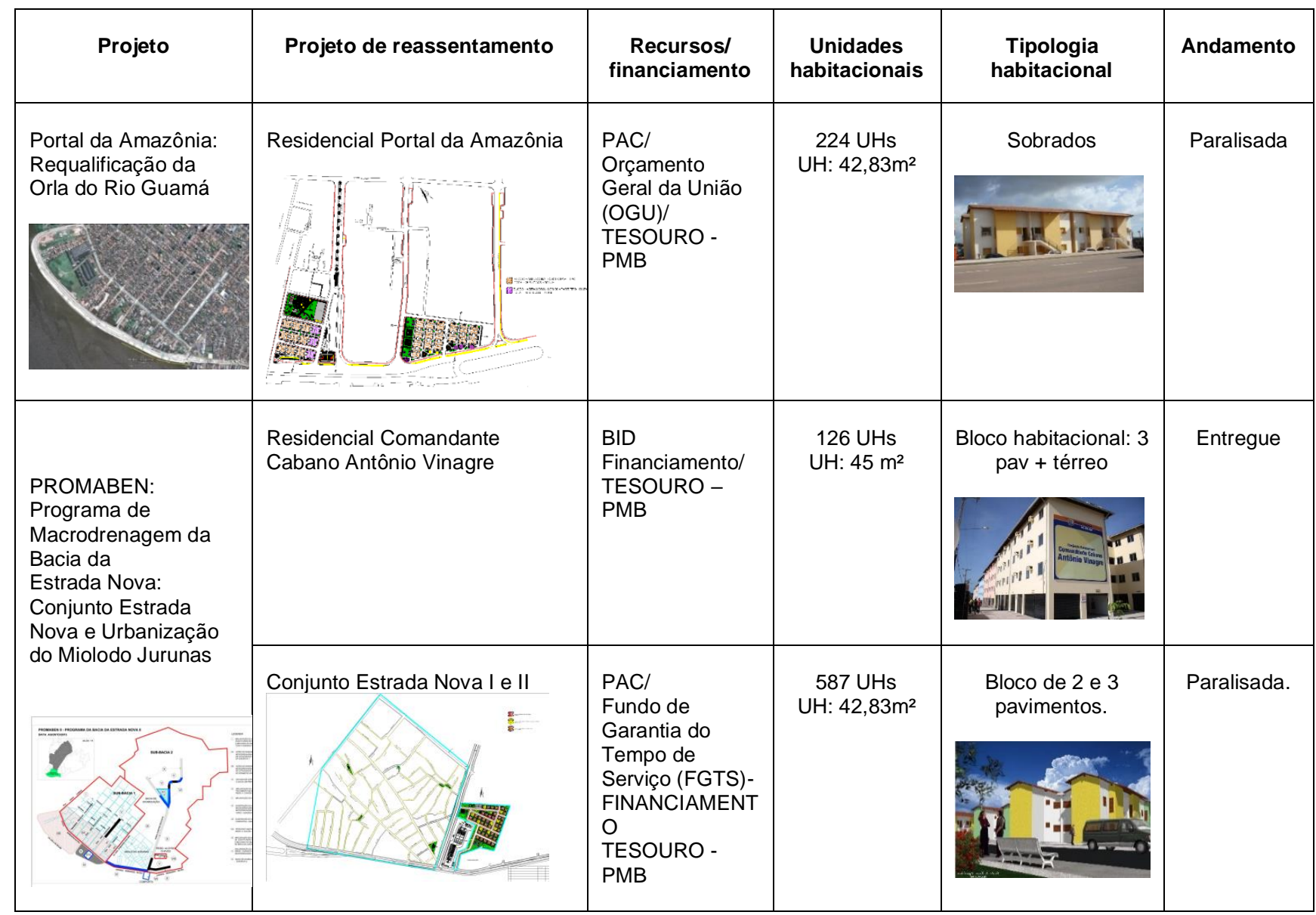

Quadro 5 - Síntese do projeto. Fonte: Prefeitura de Belém $(2011,2012)$ adaptado por autores.

\section{CONSIDERAÇÕES FINAIS}

A partir da análise, observou-se que a questão ambiental é relevante em Belém, sendo uma das principais características a presença de cursos d'água nos projetos de urbanização. Desta forma, a necessidade de obras de macrodrenagem são frequentes no planejamento da cidade, no entanto, observa-se que frente aos novos desafios que a questão ambiental impõe, há uma dificuldade de os projetos articularem urbanização, 


\section{SÃOPAULO15 17 LISBOA $25 \sim 26$ JUN 2020}

moradia e requalificação ambiental. Em geral, os projetos adotam projetos de drenagem convencionais que não preservam as características naturais das APPs, neste sentido, o projeto Taboquinha destaca-se ao propor a preservação das margens do igarapé.

Confirma-se a questão habitacional como um dos grandes imbróglios nos projetos apresentados, o adensamento das baixadas, fazem com que um número considerável de remoções seja realizado para a execução de obras de infraestrutura. A provisão habitacional torna-se elemento importante, frente a precariedade das moradias, como forma de realocar as famílias deslocadas por conta do projeto. No entanto, as problemáticas nas obras dos projetos habitacionais são frequentes, nota-se a demora na execução e/ou paralisações das unidades habitacionais, e conforme a demora nas obras, ocorre ocupações de famílias nas obras inacabadas e resistência a remoções pela incredulidade dos moradores, que possuem baixa confiança em relação a soluções de reassentamento.

Somada mais de uma década de projetos de reassentamentos inconclusos, demonstra-se que os projetos estudados se tornam exemplos de remoções forçadas, por não garantirem moradia digna aos moradores atingidos pelas obras de urbanização, desrespeitando o direito à moradia e a cidade dessa população. Portanto, observa-se uma dificuldade no planejamento e na gestão de projetos de urbanização de assentamentos precários em Belém, sobretudo no âmbito dos projetos de reassentamento. Considera-se necessário o avanço de diretrizes para habitação queatendam critérios urbanísticos e arquitetônicos que possam garantirmaior qualidade ambiental e adequação aos contextos locais daregião norte do país.

\section{BIBLIOGRAFIA}

ABELÉM, A. (1989). Urbanização e remoção: por que e para quem? Belém: UFPA/CFCH; NAEA. 165 p. (Coleção igarapé).

AFLALO, A (2016). Nova Vila da Barca em Belém, Pará: Considerações Sobre o Programas Habitacionais e o Projeto de Habitação e Urbanização. São Paulo.

BORGES, R. (2017). Unidades Habitacionais dos Residenciais Liberdade e Riacho Doce serão entregues. COHAB PA-Serviço de Informação ao Cidadão, Belém, 01 de nov. 2017. Disponível em: $<$ http://www.cohab.pa.gov.br/artigos/unidades-habitacionais-dos-residenciais-liberdade-e-riacho-doceser\%C3\%A3o-entregues > Acessado em 15 de Fevereiro de 2019.

FREITAS, L. (2014).Apresentação do projeto de habitação e urbanização da vila da barca. Belém. FOLHA DE SÃO PAULO (2019). Famílias em Belém vivem sobre o lixo a espera de obra iniciada em 2006. JORNAL FOLHA DE SÃO PAULO. 22.out. 2018. Disponível em:<https://www1.folha.uol.com.br/cotidiano/2019/10/familias-em-belem-vivem-sobre-o-lixo-a-espera-deobra-iniciada-em-2006.shtml> Acessado em 14 de fevereiro de 2020.

IBGE (2011). Aglomerados subnormais, primeiros resultados. Instituto Brasileiro de Geografia e Estatística. Rio de Janeiro.

LEÃO, M. (2013). Remoção e reassentamento em baixadas de Belém: Estudos de caso de planos de reassentamento (1980-2010). Dissertação de mestrado, Programa de Pós-Graduação em Arquitetura e Urbanismo, Universidade Federal do Pará. Belém. 


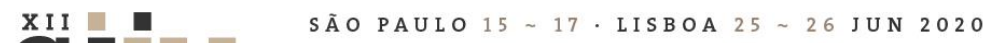

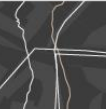

LEÃO, M. (2018). A questão habitacional em projetos do PAC urbanização de assentamentos precários em Belém/PA. In: Anais do III SEMINÁRIO NACIONAL SOBRE URBANIZAÇÃO DE FAVELAS - URBFAVELAS. Salvador.

MEIA DOIS NOVE (2010). Conjunto Residencial Comunidade Liberdade I e II, Belém - Pará (2008). Memoriais da MeiaDoisNove. 2010.2 Abril, 2 Disponível em:<http://memoriaisdameiadoisnove.blogspot.com/2010/04/conjunto-residencial-comunidade.html>Acesso em 10 de janeiro de 2019.

MOREIRA, E. (1966). Belém e sua expressão geográfica. Belém, Imprensa Universitária, 1966. In: Obras reunidas de Eidorfe Moreira, v.1, Belém.

PENTEADO, A. (1968). Belém do Pará (Estudo da Geografia Urbana). Universidade Federal do Pará. Coleção Amazônia- Série José Verissimo, v.1. Belém.

PINHEIRO, et al (2007). A questão habitacional na Região Metropolitana de Belém In: CARDOSO, A. L. Coleção Habitare - Habitação Social nas Metrópoles Brasileiras - Uma avaliação das políticas habitacionais em Belém, Belo Horizonte, Porto Alegre, Recife, Rio de Janeiro e São Paulo no final do século XX. Porto Alegre.

PINHEIRO, et al (2016). Assentamentos precários na região metropolitana de Belém: baixadas e ocupações. In: MORAES, M. P.; KRAUSE, C. NETO, V. (org) Caracterização e tipologia de assentamentos precários: estudos de caso brasileiros. Brasília: Ipea.

PONTE, J. (2015). Belém do Pará: cidade e água. In CADERNO METRÓPOLE. Volume 14 n. 33 - Mai 2015, São Paulo.

RODRIGUES, R., TAVARES, A. \& MIRANDA, T. (2016). Urbanizar as "baixadas". Experiências de projeto de urbanização de assentamentos precários em áreas de preservação permanente em Belém (PA). In: Encontro de Associação de Pesquisa e Pós-Graduação em Arquitetura e Urbanismo, Porto Alegre.

RODRIGUES, R., ARAÚJO, Q. \&CASTRO, R. (2018). URBANIZAR AS BAIXADAS: Um Balanço do PAC na Região Metropolitana de Belém. In: CARDOSO, Adauto Lúcio (org.). URBANIZAÇÃO DE FAVELAS NO BRASIL: um balanço preliminar do PAC. Primeira Edição Rio de Janeiro; Letra Capital.

SOUZA, A. \&SANTANA, J. (2013). Política Habitacional e (IM)Permanência de Famílias Remanejadas: Um Estudo Sobre o Projeto de Urbanização da Vila da Barca em Belém, Pará. R. Políticas Públicas, v.17, n.171181. São Luís.

VILLAÇA, F. (1986). O Que Todo Cidadão Precisa Saber Sobre Habitação. 